\title{
A simple technique for determining the equilibrium equivalent Thoron concentration using a CR-39 detector: Application in mineral treatment industry
}

\author{
C. Kranrod ${ }^{1,2}$, S. Chanyotha ${ }^{1}$, N. Chankow ${ }^{1}$, \\ S. Tokonami ${ }^{2}$, T. Ishikawa ${ }^{2}$ and S.K. Sahoo ${ }^{2}$ \\ ${ }^{1}$ Department of Nuclear Technology, Chulalongkorn University, 10330 Bangkok, Thailand \\ ${ }^{2}$ Research Center for Radiation Protection, National Institute of Radiological Sciences, \\ 263-8555 Chiba, Japan \\ e-mail: tokonami@nirs.go.jp
}

\begin{abstract}
The paper presents a simple technique for determination of the Equilibrium Equivalent Thoron Concentration (EETC). A solid-state nuclear alpha track detector (SSNATD) named CR-39 manufactured by BARYOTRAK is used as the detector. This technique can be utilized anywhere, provided that air sampling is carried out with a DC driving pump. Although the measurement of Thoron concentrations is useful enough for screening high Thoron exposure, it is still necessary to determine Thoron progeny concentrations in order to complete dose assessment. After applying this technique for determining the EETC in some selected areas in southern Thailand, it has been found that the obtained EETC values are consistent with the values presented in the report compiled by UNSCEAR in 2000.
\end{abstract}

\section{INTRODUCTION}

Although members of studies on radon were conducted all over the world, there have only been a few studies on thoron. It is considered that doses from thoron progeny are generally smaller than those from radon progeny in the natural environment. Since recent studies have shown that high thoron concentrations were observed in some areas, thus, the dose from thoron progeny might become significant in such areas [1-3]. According to some recent studies, occupational exposure to thoron progeny became significant and the protection against thoron progeny inhalation should be considered in the near future. In the case of radon exposure, the dose can be estimated from by the radon concentration under several assumptions. The equilibrium equivalent radon concentration (hereafter called EERC) can be obtained by the product of radon concentration and the equilibrium factor. On the other hand, it is impossible to follow the same procedure as the case of thoron exposure. Since the thoron concentration observed exponentially decreases with a distance from the source because of its short half-life (55.6s) [4], use of thoron concentration will be meaningless unless the position of measurement is known. Therefore, the equilibrium equivalent thoron concentration (hereafter called EETC) should be directly measured from the viewpoint of the dose assessment. A simple alpha-track measurement technique for determining thoron progeny concentrations using a CR-39 detector is proposed in this study.

\section{MATERIALS AND METHOD}

The measurement system consists of two separate parts: air sampling and measuring parts. Figure 1 shows a schematic diagram of the whole measurement system and materials used for the alpha-track registration system, respectively. The following procedures are very simple and can be applied for determining the equilibrium equivalent thoron concentration (EETC) in any suspected area. 
To avoid the unavailability of the electrical supply when taking air sample and making measurement, a solid-state nuclear alpha track detector (SSNATD), which is typically used for determining EERC, is selected as the detector. The SSNATD, CR-39 type detectors named "BAR-YOTRAK" which are commercially available in Japan, were used in this study. The characteristics of CR-39 detector to radon and thoron progeny are already discussed where else [5]. Air sample is taken in by a DC driven pump through a collecting media, a glass microfiber filter (Whatman, England), for about 24 hours. The air flow rate is $0.5 \mathrm{~L} / \mathrm{min}$. In order to determine thoron progeny concentration, the registration on thoron progeny has to be distinguished from that of radon progeny. Therefore, after air sampling is done, the filter is left for more than 6 hours to allow radon progeny to completely decay away. An aluminum foil with a thickness of $15 \mu \mathrm{m}\left(4.0 \mathrm{mg} . \mathrm{cm}^{-2}\right)$ is then placed on the filter in order to reduce alpha particle energy emitted from ${ }^{212} \mathrm{Po}$ and to increase the detector effectiveness. Then, the CR-39 detector is placed directly on the aluminum foil and left for about 2 days to allow registration of alpha tracks on the detector. Following the manner of etching (chemically etched for $24 \mathrm{hrs}$. in a $6 \mathrm{M} \mathrm{NaOH}$ solution at $60^{\circ} \mathrm{C}$ ) and reading the number of tracks on the SSNATD, the thoron progeny concentration can be determined.

To verify the reliability of measured values, alpha spectroscopic method is used for comparison. The results are in good agreement. Authors have an opportunity to apply this developed technique for determination of EETC in dusty areas in a mineral treatment company sited in southern Thailand. The investigated areas include one indoor area (ore receiving room) and three outdoor areas (opposite of ore receiving room, in front of ore mixing room and storage bay). It lasted for two days: February $17^{\text {th }}$ through $18^{\text {th }}, 2005$.

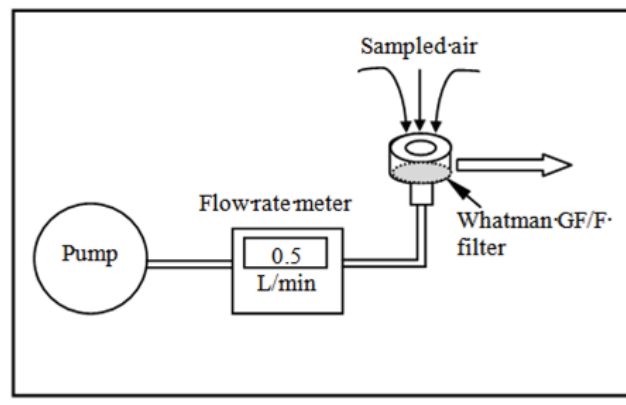

a)

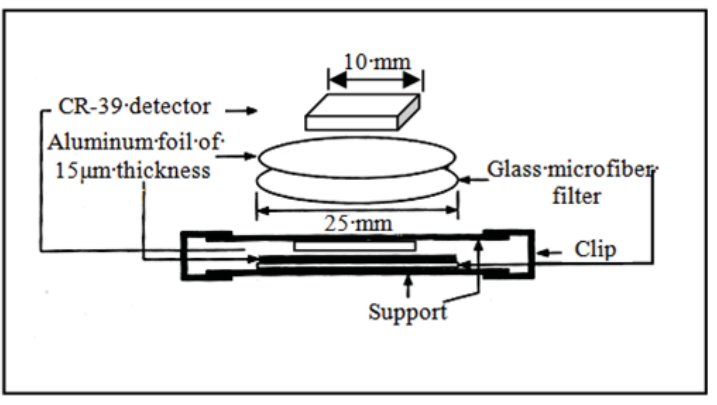

b)

Figure 1. (a) Schematic diagram of measurement system (b) Materials used for alpha-track registration.

\section{DETERMINATION OF THE EETC}

${ }^{212} \mathrm{~Pb}$ is the principal species to measure. Because of its long half-life, ${ }^{212} \mathrm{~Pb}$ can be easily separated from mixed radon progeny. Since more than $90 \%$ of EETC is dominated by the ${ }^{212} \mathrm{~Pb}$ concentration [6], its practical evaluation can be achieved even if the ${ }^{212} \mathrm{Bi}$ concentration is ignored. Then EETC can be approximately estimated from ${ }^{212} \mathrm{~Pb}$ by the following equation:

$$
\mathrm{EETC}=0.913 \mathrm{X}_{\mathrm{Pb}-212}
$$

Where $\mathrm{X}_{\mathrm{Pb}-212}$ is the concentration of ${ }^{212} \mathrm{~Pb}$ in $\mathrm{Bq} \mathrm{m}^{-3}$ and can be calculated by equation (2), then the relationship between ${ }^{212} \mathrm{~Pb}$ concentration and alpha track density can be expressed as following formula.

$$
\left(\mathrm{N}-\mathrm{N}_{\mathrm{bg}}\right) \mathrm{A}=\mathrm{I}_{\mathrm{bc}} \mathrm{X}_{\mathrm{Pb}-212} v \eta_{\mathrm{Bi}-212} 0.3594+\mathrm{I}_{\mathrm{bc}} \mathrm{X}_{\mathrm{Pb}-212} v \eta_{\mathrm{Po}-212} 0.6404
$$


Where

$\mathrm{N}=$ alpha-track density [track $\mathrm{mm}^{-2}$ ];

$\mathrm{N}_{\mathrm{bg}}=$ background alpha-track density [track $\left.\mathrm{mm}^{-2}\right]$;

$\mathrm{A}=$ effective area of filter $\left[\mathrm{mm}^{2}\right]$;

$v=$ flow rate $\left[\mathrm{m}^{3} \mathrm{~s}^{-1}\right]$

$\mathrm{I}_{\mathrm{bc}}=$ The number of alpha tracks registered as a result of ${ }^{212} \mathrm{~Pb}$ decay $\left[\mathrm{s}^{2}\right]$

$\eta_{\mathrm{Bi}-212}, \eta_{\mathrm{Po}-212}=$ detection efficiency of alpha particles emit from ${ }^{212} \mathrm{Bi}$ and ${ }^{212} \mathrm{Po}$, respectively.

Assuming that the detection efficiencies are equal to geometric detection efficiencies. Tokonami [5] reported that the CR-39 detection efficiencies for ${ }^{212} \mathrm{Bi}$ and ${ }^{212} \mathrm{Po}$ were estimated to be $28.9 \%$ and $17.2 \%$, respectively. Thus, equation (2) can be rewritten as follows

$$
\mathrm{X}_{\mathrm{Pb}-212}=\frac{\left(\mathrm{N}-\mathrm{N}_{\mathrm{bg}}\right) \mathrm{A}}{0.2139 \mathrm{I}_{\mathrm{bc}} v}
$$

The number of alpha tracks registered $\left(\mathrm{I}_{\mathrm{bc}}\right)$ as a result of ${ }^{212} \mathrm{~Pb}$ decay after air sampling can be calculated as follows

$$
\begin{aligned}
\mathrm{I}_{\mathrm{bc}}= & \frac{\lambda_{\mathrm{c}}}{\lambda_{\mathrm{b}}^{2}\left(\lambda_{\mathrm{c}}-\lambda_{\mathrm{b}}\right)} \mathrm{e}^{-\lambda_{\mathrm{b}} \mathrm{T}_{\mathrm{w}}}\left(1-\mathrm{e}^{-\lambda_{\mathrm{b}} \mathrm{T}_{\mathrm{s}}}\right)\left(1-\mathrm{e}^{-\lambda_{\mathrm{b}} \mathrm{T}_{\mathrm{m}}}\right) \\
& +\frac{\lambda_{\mathrm{c}}}{\lambda_{\mathrm{c}}^{2}\left(\lambda_{\mathrm{b}}-\lambda_{\mathrm{c}}\right)} \mathrm{e}^{-\lambda_{\mathrm{c}} \mathrm{T}_{\mathrm{w}}}\left(1-\mathrm{e}^{-\lambda_{\mathrm{c}} \mathrm{T}_{\mathrm{s}}}\right)\left(1-\mathrm{e}^{-\lambda_{\mathrm{c}} \mathrm{T}_{\mathrm{m}}}\right)
\end{aligned}
$$

Where

$\mathrm{T}_{\mathrm{s}}=$ sampling period $[\mathrm{s}]$;

$\mathrm{T}_{\mathrm{w}}=$ elapsed time after sampling [s];

$\mathrm{T}_{\mathrm{m}}=$ measurement period $[\mathrm{s}]$;

$\lambda_{\mathrm{b}}, \lambda_{\mathrm{c}}=$ decay constants of ${ }^{212} \mathrm{~Pb}$ and ${ }^{212} \mathrm{Bi}$, respectively.

\section{RESULTS AND DISCUSSIONS}

The result from comparative test of the EETC between the studied technique and alpha spectroscopic method is shown in figure 2. The two methods exhibit a relatively good relative agreement, which indicates that this technique is suitable for determination of EETC in field measurements.

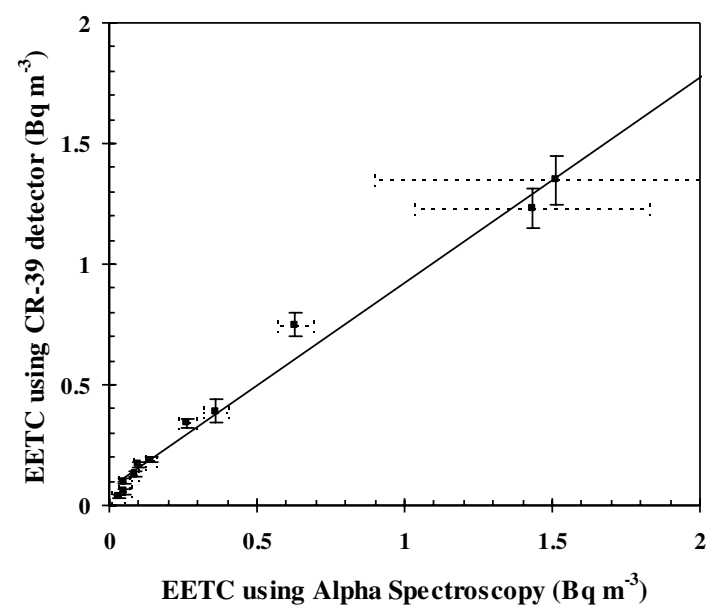

Figure 2. Comparison of the calculated EETC values between the developed technique and the alpha spectroscopy. 
The results of EETC carried out in field measurement are summarizes in table 1. It shows that, the EETC (0.12) obtained from the indoor location; ore receiving room where stored the raw material; is higher than the EETC (0.07) of the outside the room about $40 \%$. In addition, the highest EETC is found in front of the bay where the TENORM waste was stored. Nevertheless, the EETC values obtained from this simple method are consistent with the values presented in the report compiled by UNSCEAR [6].

Table 1. Indoor and outdoor of EETC values in measured areas of a mineral treatment industry.

\begin{tabular}{|l|l|}
\hline Location & EETC $\left(\mathrm{Bq} \cdot \mathrm{m}^{-3}\right)$ \\
\hline Indoor & \\
\hline Ore receiving room & 0.12 \\
\hline East Asia [6] & $0.03-1.8$ \\
\hline Outdoor & \\
\hline In front of ore receiving room & 0.07 \\
\hline In front of ore mixing room & 0.15 \\
\hline In front of storage bay & 0.23 \\
\hline East Asia [6] & $0.04-2.5$ \\
\hline
\end{tabular}

\section{CONCLUSIONS}

A simple alpha-track measurement technique using a CR-39 detector can be used to determine the thoron progeny concentrations and to evaluate the EETC values. This technique also provides unlimited use in any suspected area of high thoron exposure, as long as air sampling is carried out with a DC driven pump.

\section{Acknowledgments}

Parts of this study were financially supported by the Thai government and Private sectors co-operation. In addition, all of materials and the performance tests of this study were supplied by the Research Center for Radiation Protection of National Institute of Radiological Sciences. The authors would like to thank them for their cooperation.

\section{References}

[1] Doi M. and Kobayashi S., Health Phys, 66, (1994) 274-282.

[2] Ma J. et al., Health Phys, 72, (1997) 86-91.

[3] Chung W.H. et al., Radiat Prot Dosim, 80, (1998) 423-426.

[4] Doi M. et al., Health Phys, 66, (1994) 43-49.

[5] Tokonami, S., et al., Jpn. J. Health Phys, 37(1), (2002) 59-63.

[6] United Nations Scientific Committee on the Effects of Atomic Radiation, Sources and effects of ionizing radiation, (United Nations, New York, 2000) pp 84-155. 